\title{
Power Quality Improvement Based on Five-Level Shunt APF Using Sliding Mode Control Scheme Connected to a Photovoltaic
}

\author{
Yousfi Abdelkader*‡, Tayeb Allaoui**, Chaker Abdelkader*** \\ * Department of Electrical Engineering, University Djilali Bounaama Khemis Miliana, Algeria \\ **Department of Electrical Engineering Laboratory LGEGI, University of Tiaret, Algeria \\ *** Department of Electrical Engineering ,Laboratory SCAMRE, E.N.P \\ Oran BP 1742 El’ M’naouer, Oran, Algeria. \\ (yousfi_pg@yahoo.fr, allaoui_tb@yahoo.fr, chakeraa@yahoo.fr)
}

${ }^{\ddagger}$ Corresponding Author; A. Yousfi, Rue theniet el-had Khemis Miliana, 44225 Ain Defla, Algeria

Fax: +213 776867 326, yousfi_pg@yahoo.fr

Received: 25.11.2017 Accepted:30.12.2017

\begin{abstract}
This paper presents a compensating system for the harmonic currents, the reactive power in three-phase distribution system by using a five-level inverter based shunt active power filter (SAPF) connected by a photovoltaic system. A controller based on the $\mathrm{p}-\mathrm{q}$ theory is introduced for the SAPF. The distribution network which supplies non-linear load and employing five-level inverter based SAPF connected by a photovoltaic system is simulated by MATLAB/SIMULINK software. The performance of SAPF is analyzed by using the proposed control technique on the total harmonic distortion of source current, power factor and reactive power. Besides, it is illustrated by extensive simulation results, the effectiveness of five-level SAPF connected by a photovoltaic system.
\end{abstract}

Keywords- Active Power Filter Shunts (APFs); p-q Theorem; Harmonic currents Power quality; Sliding Mode Controller (SMC); Photovoltaic.

\section{Introduction}

The widespread use of power electronic equipments as the non-linear loads in power distribution system cause several power quality problems such as harmonic currents and poor power factor. These power quality problems are the major concern as utilities are moving forward to a Smart Grid. Power quality for the digital economy in a Smart Grid distribution system is a priority which involves various options of quality and price is a priority. Meanwhile, the impact of renewal sources of energy like solar, wind, wave etc., which mainly use power electronic controllers and integrated into the Smart Grid cause increased power quality problems [1]-[6]. A two level voltage source inverter based SAPF to compensate harmonic currents and reactive power in industrial networks was already established [1]-[7].

The controller is the heart of the active power filter and a lot of research is being conducted in recent years. Conventional PI voltage and current controllers have been used to control the harmonic current and dc voltage of the shunt APLC. Recently, sliding mode controllers are used in power electronic system and drive applications [2].

This paper presents a compensating system for the harmonic currents, the reactive power in three-phase distribution system by using a five-level inverter based shunt active power filter (SAPF) connected by a photovoltaic system. A controller based on the p-q theory is introduced for the SAPF. The distribution network which supplies non-linear load and employing five level inverter based SAPF connected by a photovoltaic system is simulated by MATLAB/SIMULINK software. The performance of SAPF is analyzed by using the proposed control technique on the total harmonic distortion of source current, power factor and reactive power. Besides, it is illustrated by extensive simulation results, the effectiveness of five-level SAPF connected by a photovoltaic system.

\section{Shunt Active Power Filter (SAPF)}

Active filters are special equipments that use power electronic converters to compensate for current and/or 
voltage harmonics originated by non-linear loads, or to avoid that harmonic voltages might be applied to sensitive loads (Fig.1).

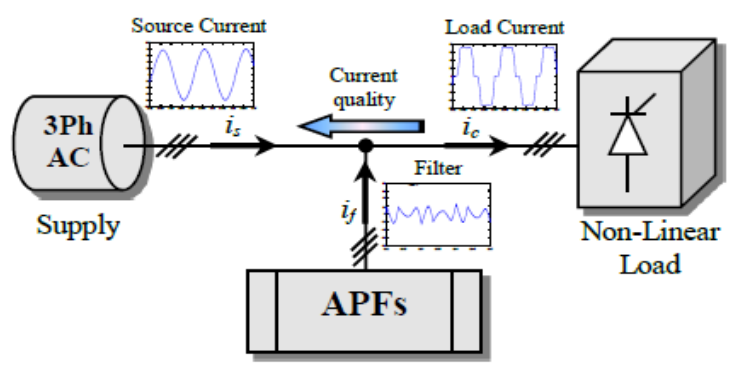

Fig. 2 presents the electrical scheme of a shunt active filter for a three-phase power system. which, can both compensate for current harmonics and perform power factor correction. Furthermore, it allows load balancing. The power stage is, basically, a voltage-source inverter with only a single capacitor in the DC side (the active filter does not require any internal power supply), controlled in a way that it acts like a current-source. From the measured values of phase voltages $\left(v_{a}, v_{b}, v_{c}\right)$ and load currents $\left(i_{a}\right.$, $\left.i_{b}, i_{c}\right)$, the controller calculates the reference currents $\left(i_{f a}^{*}\right.$, $\left.i_{f b}^{*}, i_{f c}^{*}\right)$ used by the inverter to produce the compensation currents $\left(i_{f a}, i_{f b}, i_{f c}\right)$.

Figure 1. Active Power Filter shunt principle schematics

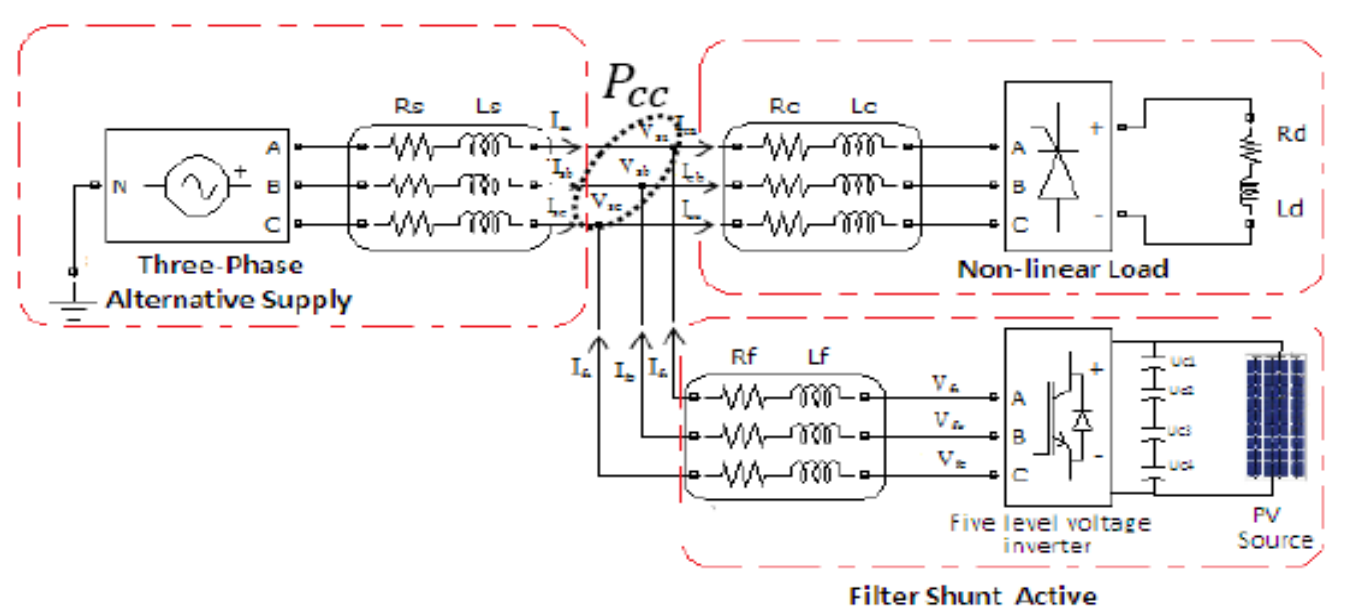

Figure 2. Equivalent schematic of APFs

Fig. 3 shows the block diagram of the Shunt Active Filter powered by a photovoltaic source controlled by sliding mode.

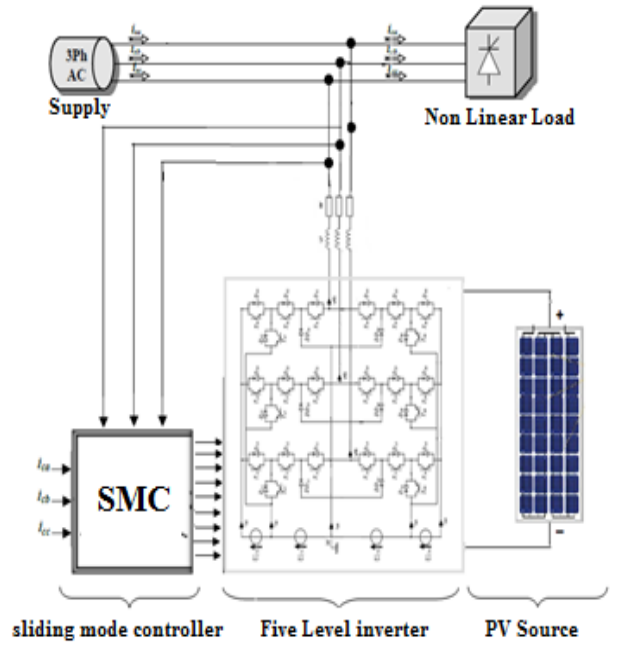

Figure 3. Block diagram of an Active Power Filter Shunt controlled by sliding mode

\section{Sliding mode Control of the Application Control of the Shunt Active Power Filter}

The sliding mode control is to reduce the state trajectory to the sliding surface and evolve on the latter with a certain dynamic to the point of balance. The design of sliding mode controller supports the desired stability problems and performance in a systematic way. The implementation of this control method requires three main steps. The first is the choice of the surface and then the convergence condition finally calculating the command.

- The choice of the sliding surface not only concerns the necessary number of surfaces, but also their form and according to the application and objective. JJ Slotine [10] provides a general equation of the form to determine the sliding surface ensuring the convergence of a variable to the desired value: 


$$
S(X)=\left(\frac{\partial}{\partial t}+\lambda_{X}\right)^{r-1} e(X)
$$

With: $X_{\text {ref }}-X$

$e(x)$ : Departure from variable to adjust $e(x)=$

$X$ : Positive constant that interprets the band pass the desired control.

$r$ : Relative degree, equal to the number of times that we must derive the output to display the command.

$S(X)=0$ : A linear differential equation which the only solution is $e(x)=0$.

- The convergence condition is the first condition that allows the dynamics of the system to converge to the sliding surface. We retain literature direct switching function proposed by Emilianov Utkin [11] and can be made by the following sufficient condition:

$$
S(X) \cdot \dot{S}(X)<0
$$

- The control is calculated to bring the variable to be controlled to the surface, and then, towards its equilibrium point by holding the condition of existence of the sliding mode. Therefore let:

$$
U(t)=U_{e q}+U_{n}
$$

$U_{e q}$ : Is the equivalent command proposed by Utkin. It is calculated assuming that the system behavior during the drag mode is described by $\dot{S}(X)=0$. This command can be interpreted as the modulated average that takes control when fast switching between $U_{\min }$ and $U_{\max }$.

A command $U_{n}$ is determined to ensure the attractiveness of the variable control to the sliding surface and satisfy the convergence condition. The simplest function is as a relay.

$$
\left\{\begin{array}{l}
U_{n}=k \cdot \operatorname{sign} S(X) \\
k>0
\end{array}\right.
$$

A "k" high may cause the phenomenon of chattering can be reduced by replacing the relay function by a continuous function (smooth), defined by (5) where $\lambda$ is a parameter defining the degree of attenuation of the oscillations.

$$
U_{n}=k \cdot \frac{S(X)}{|S(X)|+\lambda}
$$

The application to the control by sliding mode to control the filter gives us:

From the equations modeling the active filter:

$$
R_{f} I_{f K}+L_{f} \frac{d I_{f K}}{d t}=N_{g K} U_{c}-V_{K}
$$

The controlled variable is the output current of the active filter. For this we selected the sliding surface as follows:

$$
S=I_{\text {fref }}-I_{f}
$$

One result is the derivative of the surface:

$$
\dot{S}=\frac{d I_{\text {fref }}}{d t}-\dot{I}_{f}
$$

During the convergence mode, one must satisfy the condition $\mathrm{S}(\mathrm{X}) \cdot \dot{\mathrm{S}}(\mathrm{X})<$. To reduce the chattering phenomenon is a continuous function chosen for the attractive command:

$$
U_{n}=-k \frac{s}{|S|+\lambda}
$$

From the above equations, and taking into account the condition of sliding zero speed $\dot{S}$, we get the control law and composed of equal parts attractive:

$$
N_{g K}=\frac{1}{U_{c}}\left(R_{f} I_{f K}+L_{f} \frac{d I_{\text {frefK }}}{d t}+V_{K}+L_{f} K \frac{s}{|S|+\lambda}\right)
$$

\section{PV Model}

A solar cell is basically a p-n junction fabricated in a thin wafer of semiconductor. The electromagnetic radiation of solar energy can be directly converted to electricity through photovoltaic effect. Being exposed to the sunlight, photons with energy greater than the bandgap energy of the semiconductor creates some electronhole pairs proportional to the incident irradiation. To find the model of the photovoltaic generator, we must start by identifying the electrical equivalent circuit to that source. Many mathematical models have been developed to represent their highly nonlinear characteristics resulting from that of semiconductor junctions that are the major constituents of PV modules. There are several models of photovoltaic generators which have a certain number of parameters involved in the calculation of voltage and current output. In this study, we will present the model of single diodes (Fig.4) taking into account the shunt and series resistances of the PV cell.

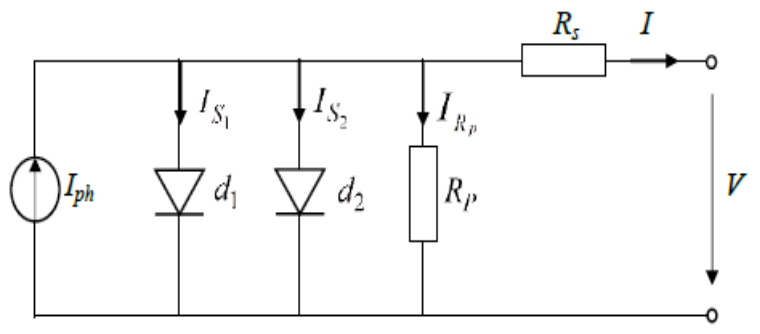

Figure 4. Model of a photovoltaic cell

The current source $I_{p h}$ represents the cell photocurrent. $R_{p}$ and $R_{s}$ are the intrinsic shunt and series resistances of the cell, respectively. Usually the value of $R_{p}$ is very large and that of $R_{s}$ is very small, hence they may be neglected to simplify the analysis. PV cells are grouped in larger units called PV modules which are further interconnected in a parallel-series configuration to form PV arrays [8] [9]. 
The photovoltaic panel can be modelled mathematically as given in equations (11) - (14)

$$
\begin{array}{r}
I=I_{p h}-I_{S 1}\left[e^{\frac{q\left(V+I R_{s}\right)}{k T}}-1\right]-I_{s 2}\left[e^{\frac{q\left(V+I R_{s}\right)}{A k T}}-1\right]-\frac{V+I R_{s}}{R_{p}} \\
I=I_{p h}-I_{S}\left[e^{\frac{q\left(V+I R_{s}\right)}{k T}}-1\right]-\frac{V+I R_{s}}{R_{p}}
\end{array}
$$

Working backwards from the equations, an equivalent circuit can be easily determined, and this aids development of the simulation model. This equivalent circuit is shown in figure 5.

$$
I_{p h}=I_{s c}
$$

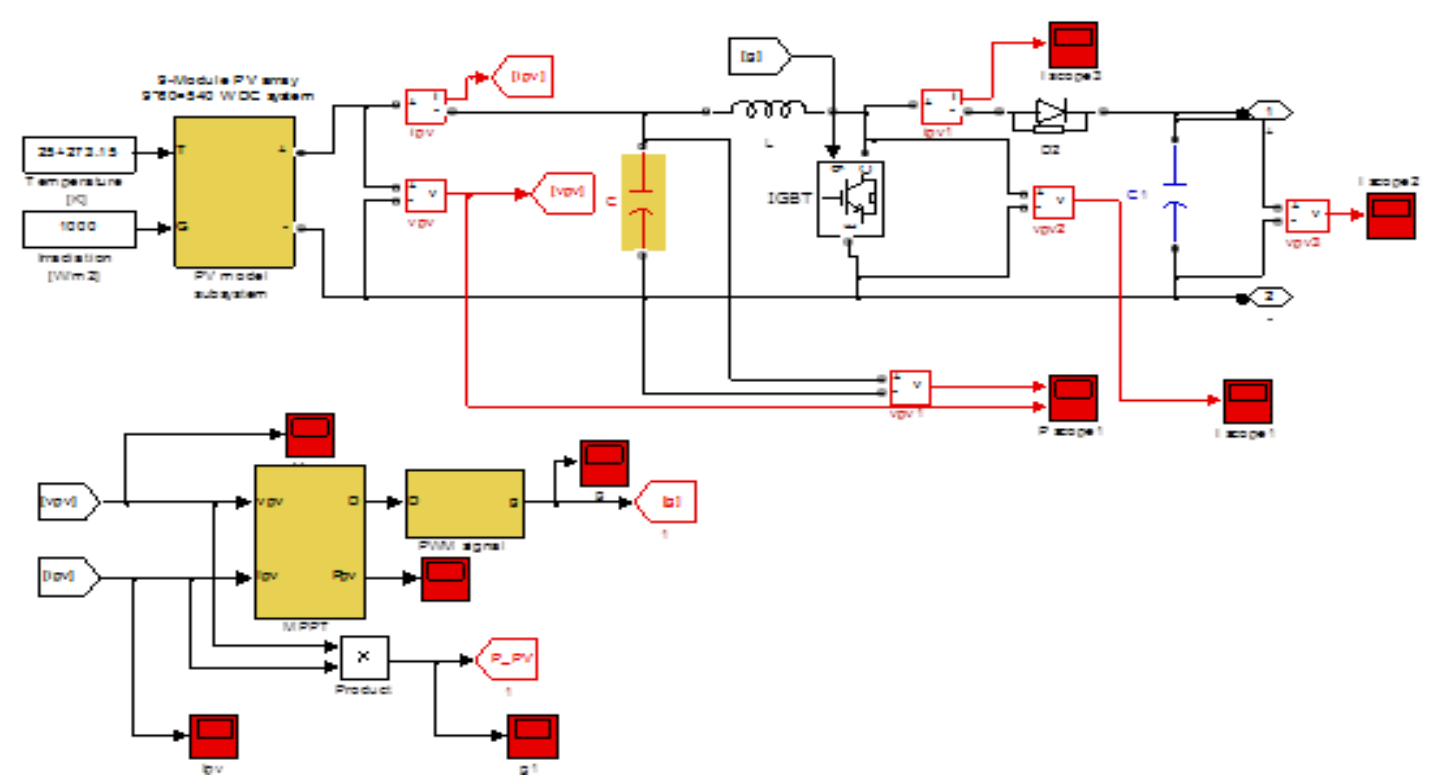

Figure 5. Photovoltaic system developed with Matlab/Simulink

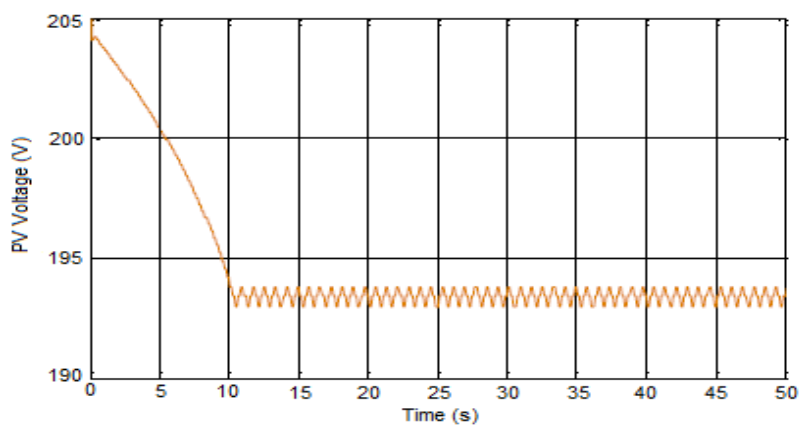

Figure 6. $\mathrm{PV}$ array voltage $V_{P V}$

$$
I_{S}=\frac{I_{p h}}{\left(\exp \left(\frac{V_{o c}}{0.25 e c}\right)-1\right)}
$$

The photovoltaic system includes:

- $\quad$ Nine photovoltaic modules (60 Watt of power each and $1000 \mathrm{~W} / \mathrm{m}^{2}$ of irradiation);

- $\quad$ PV array operates at MPP: $P_{P V}=9 * 60=540 \mathrm{~W}$;

- $\quad$ Maximum Power Point Tracking controller (MPPT);

- Boost converter (DC/DC) that steps-up a DC input voltage.

\section{Simulation Results}

\subsection{Photovoltaic system}

Figure 5 shows the voltage value obtained by the photovoltaic array and feeds the dc/dc converter, or $\left(\mathrm{V}_{\mathrm{PV}}=\right.$ $193.5 \mathrm{~V})$. 


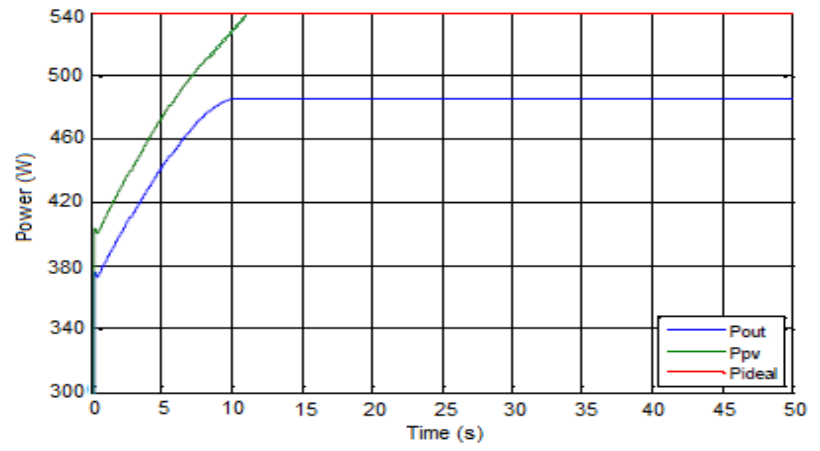

Figure 8. $P V$ array output power $P_{P V}$ compared to ideal $P_{\text {ideal }}$ and MPP $P_{\text {out }}$.

\subsection{Active Power Filter shunt}

The Simulink toolbox in the Matlab software in order to model and test the system using P-Q algorithm method then sliding mode controller. The system parameters values are summarized in Table 2.

Table 2. Simulation parameters common to the applications considered

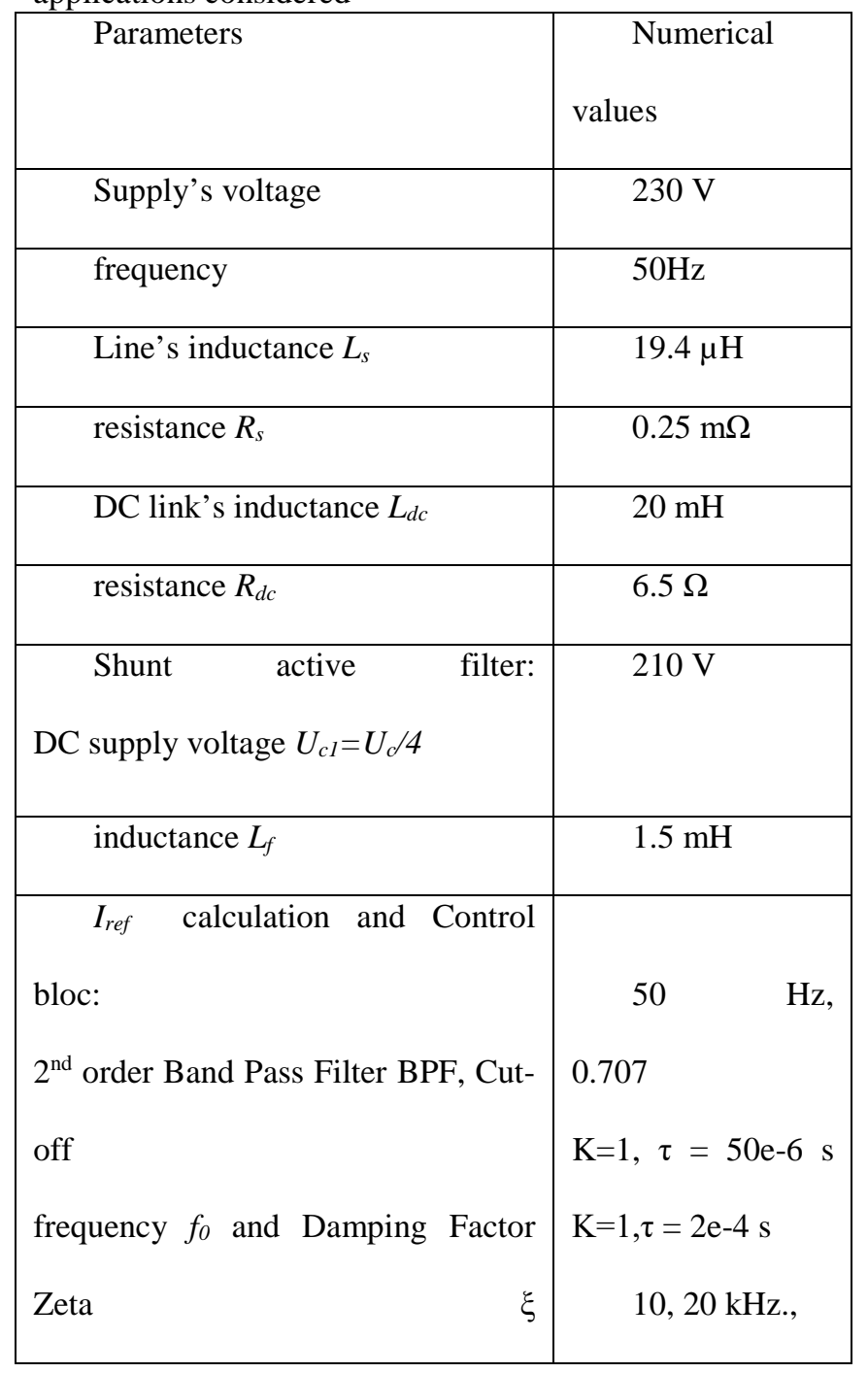

\begin{tabular}{|l|l|}
\hline $1^{\text {st }}$ order Low Pass Filter: $i_{f}$ LPF, $i_{\text {ref }}$ & $5 \mathrm{kHz}$ \\
LPF, & \\
Carrier bipolar saw-toothed, signal & \\
magnitude and frequency, Switching & \\
frequency & \\
\hline inductance $L_{C}$ & $1.5 \mathrm{mH}$ \\
\hline
\end{tabular}

\section{3 Characteristics of the Current of Source before} Active Filtering

The graphs of the load current before application of the active filter are shown in Fig. 9, 10. Symmetrical current distortion $i_{c a}$ there is from the point of half period (see Fig. 10), which means that multiple harmonics 2 and 3 are absent in the spectrum of $i_{c a}$ and only those of rank (6h \pm 1 ) are present, this is confirmed by the spectrum of $i_{c a}$ (see Figure 10) representing the first 30 harmonics more meaning, with a THD $\left(i_{c a}\right)$ of $19.99 \%$ for an observation period of $0.1 \mathrm{~s}$.

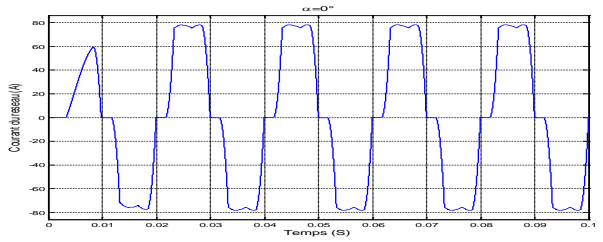

Figure 9. Allure $i_{c a}$ before active filtering

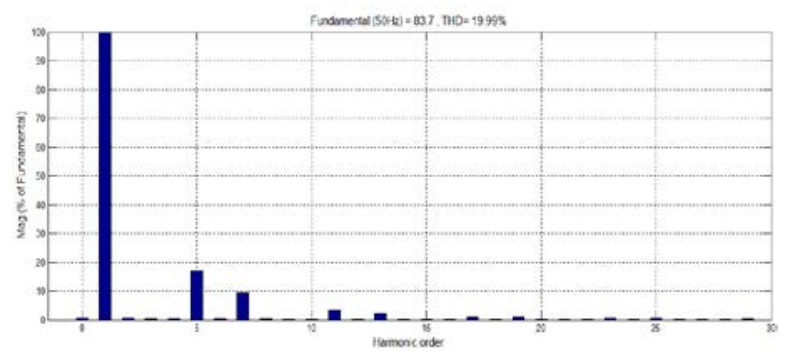

Figure 10. Harmonic Spectrum $i_{c a}$

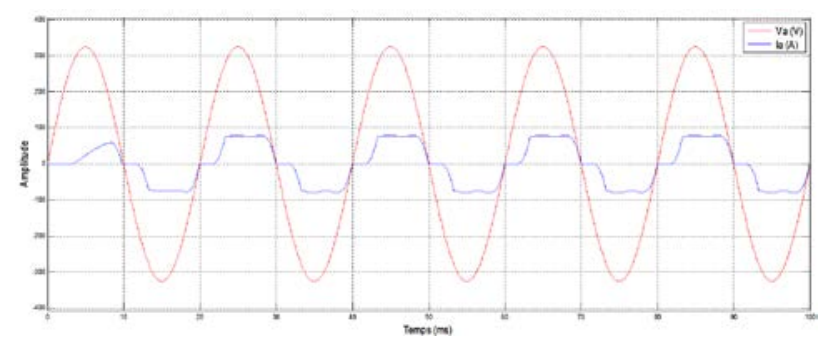

Figure 11. Allures load current $i_{c a}$ shifted to the supply voltage $v_{s a}$ without active filtering 


\section{4 Characteristics of the Current of Source after Active} Filtering

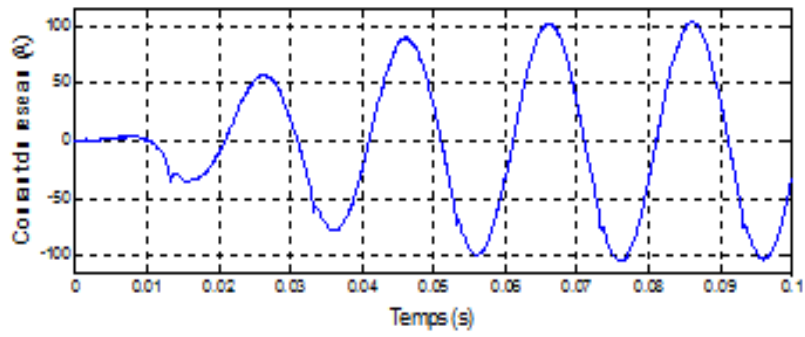

Figure 12. Supply current waveform after compensation

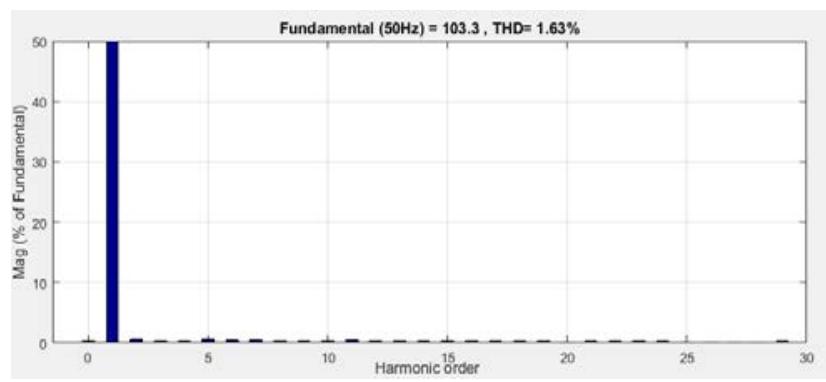

Figure 13. Harmonic spectrum of ica after compensation

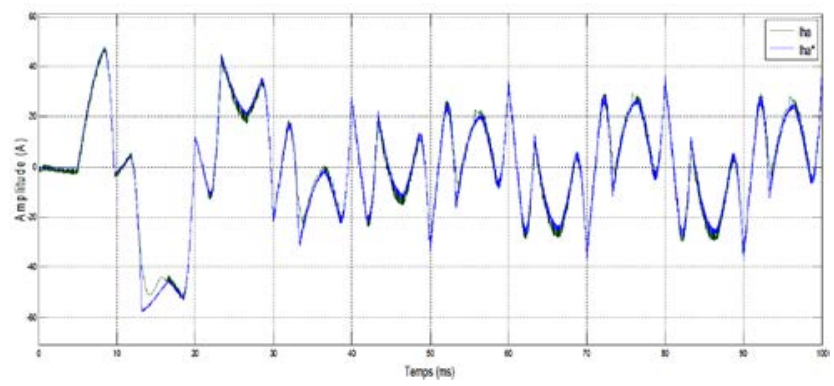

Figure 14. APF current and its reference with sliding mode correctors

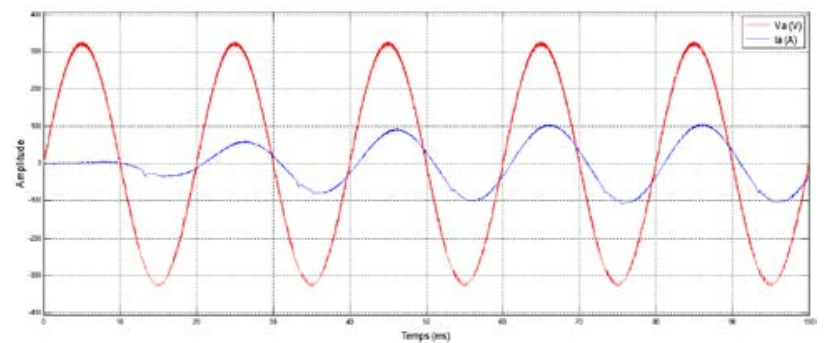

Figure 15. Current and voltage waveforms after compensation

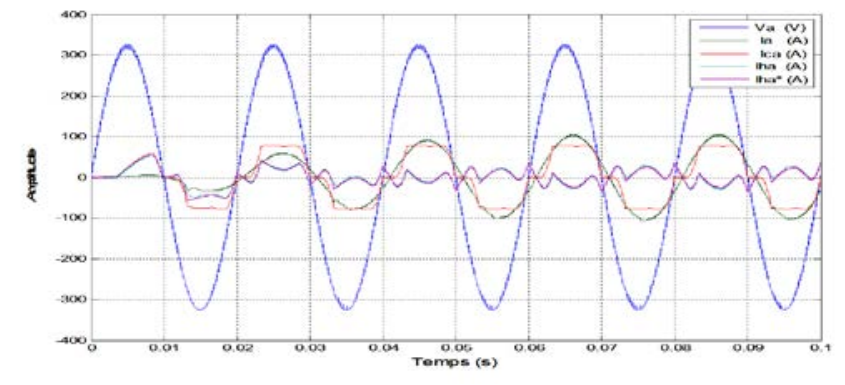

Figure 16. Load current non-linear $i_{c a}$, source current $i_{s a}$ and of the active filter $i_{f a}$

\section{Conclusion}

The results obtained in this modest work allow us to visualize the effectiveness of a five-level shunt active power filter (APFs) using a sliding mode controller. In fact, the harmonic distortion THD drops from $19.99 \%$ to $1.63 \%$ after using the active filter. Thus the power factor has been fixed, that is to say voltage and current became in phase.

For future work, we plan to extend our study to other structures, however, the number of levels of the inverter used. Then we will see the comparison between them. Also, we intend to consider a pollution load with more than $19.99 \%$ of total harmonic distortion.

\section{References}

[1] Grino R, Cardoner R, Costa-Castello R, and Fossas E. «Digital repetitive control of a three-phase four-wire shunt active filter». IEEE Transactions on Industrial Electronics; 2007; vol. 54, no. 3, pp. 1495-1503.

[2] Ali Reza Reisi, Mohammad H. Moradi, Hemen Showkati, " Combined photovoltaic and unified power quality controller to improve power quality ", Solar Energy, no. 88, pp. 154-162, 2013.

[3] Fabio L. Albuquerque, Adelio J. Moraes, Geraldo C. Guimaraes, Sergio M.R. Sanhueza, Alexandre R. Vaz, " Photovoltaic solar system connected to the electric power grid operating as active power generator and reactive power compensator », Solar Energy, Volume 84, Issue 7, pp. 1310-1317, July 2010.

[4] K. Ilango, P.V. Manitha, G.Nair Manjula, « Modified ICos $\Phi$ Controller for Shunt Active Filter Interfacing Renewable Energy Source and Grid»,AASRI Conference on Power and Energy Systems, Volume 2, pp. 62-68, 2012.

[5] Karuppanan p. and Mahapatra k.k., «PI with Fuzzy Logic Controller based APLC for compensating harmonic and reactive power. Communication and Power Engineering», ACEEE, July 28-29, 2010.

[6] Abdalla, I.I.; Rao, K.S.R.; Perumal, N. , "Harmonics mitigation and power factor correction with a modern three-phase four-leg shunt active power filter," 2010 IEEE International Conference on Power and Energy (PECon), vol., no., pp.156-161, Nov. 29 2010-Dec. 1 2010.

[7] T. Messikh, S. Mekhilef, and N. A. Rahim; "Adaptive Notch Filter for Harmonic Current Mitigation”, 
International Journal of Electrical, Computer, Energetic, Electronic and Communication Engineering Vol:2 No: 10, 2008.

[8] Ramdan B. A. Koad, Ahmed. F. Zobaa : « Comparison between the Conventional Methods and PSO Based MPPT Algorithm for Photovoltaic Systems». International Journal of Electrical, Computer, Energetic, Electronic and Communication Engineering Vol:8 No: 4, 2014.
[9] Khelfi, D., Mazari, B., Ferdi, B., Three phase 5-level PWM inverter for grid connected photovoltaic system, (2013) International Review of Automatic Control (IREACO), 6 (1), pp. 1-8.

[10] J-J. Slotine, W. Li, Applied Nonlinear Control, Prentice Hall, 1991.

[11] V.I.Utkin "Sliding mode control design principles and application to electric drives", IEEE Trans On Elect,Vol 40 feb 93, pp23-36. 